RU Опыт построения типологии предлогов (на материале русского, английского и немецкого языков)

\author{
Салеева (Зайцева) Е. М.
}

\begin{abstract}
Аннотация. Цель исследования - составить многоуровневую типологическую классификацию предлогов русского, английского и немецкого языков, позволяющую эксплицировать и определить возможные причины нарушения употребления данных предлогов в исследуемых языках. Научная новизна работы заключается в систематизации знаний о предлогах в русле универсализации, введении в терминооборот понятий, характеризующих предлоги как конвенционально ударные, конверсионные, деривативные, коппулативные, комплементарные. Полученные результаты показали факты изо-, аллои эндоморфизма в системе предлогов сопоставляемых языков. В соответствии с принципами открытой таксономии, было выделено 9 групп предлогов, далее членимых на несколько уровней и 42 подгруппы.
\end{abstract}

EN On Typology of Prepositions
(by the Material of the Russian, (by the Material of the Russian, English and German Languages)

\author{
Saleeva (Zaytseva) E. M.
}

\begin{abstract}
The research objective includes developing a multi-level typology of the Russian, English and German prepositions with a view to identify motives for their non-standard use in the languages under study. The author summarizes results of studying the prepositions, proposes a universal typology of the prepositions (conventionally stressed, conversional, derivative, copulative, complementary), which constitutes scientific originality of the paper. The conducted analysis allows identifying isomorphic, allomorphic and endomorphic features of prepositions in the analyzed languages. Following the open taxonomy principle, the researcher distinguishes nine groups of prepositions which are then subdivided into levels and classified into forty two subgroups.
\end{abstract}

\title{
Введение
}

В типологически различных группах языков предлоги входят в состав базовых единиц языка, играют важную синтаксическую роль, служат языковыми репрезентантами внелингвистических объективных категорий времени, пространства и являются частью языковой картины мира, которая хранит в себе национально и культурно обусловленные стереотипы видения внешнего мира.

Актуальность настоящего исследования объясняется постоянно возрастающим интересом современной лингвистики и переводоведения к сопоставительным и сравнительным исследованиям современного многокультурного пространства, в котором функционируют предлоги русского, английского и немецкого языков.

В работах многих лингвистов затрагивается проблема предлога как части речи. Однако понимание семантики и функций предлогов значительно расходится в концепциях различных языковедов. Одни авторы отказывают предлогам в семантической и коммуникативной значимости: «редлоги ничего не называют, никаких понятий и представлений не обозначают...» [1, с. 9], а другие считают, что «предлог имеет значение в самом себе...» $[18$, с. 67] или обладает лексическим значением, хотя и весьма своеобразным: «В семантической системе предлогов открывается сложная область отвлечённых отношений, выражающих общественное понимание разнообразных связей между предметами, признаками, состояниями и действиями» [2, с. 523].

Сложность семантико-функциональной идентификации предлогов и отсутствие их единой оценки оставляют лакуны в их изучении, к числу таких лакун относится и классификация предлогов.

Типология предлогов ранее не составляла самостоятельного объекта исследования, хотя предшествующий языковедческий опыт описания предлогов, охватывающий материалы разных языков, наталкивает на необходимость систематизации накопленного разрозненного знания по вопросам их эволюции, семантики и функционирования. 
Разработка классификации предлогов представляется необходимой ввиду нескольких причин. Полученные на материале типологически разных языков с разной степенью генетического родства, результаты научных исследований носят разрозненный характер, освещая отдельные аспекты комплексной проблематики. Для перехода на новый уровень научного знания в данной области требуется осмысление данных, сопряженное с обобщением и унификацией (в целях ускорения научного поиска). Отношения внутри класса предлогов на разноязычном материале демонстрируют черты изо-, алло- и эндоморфизма. В этом аспекте представляемая типология ретроспективна. Апелляция к трем языкам, составившим базу исследования, не исчерпывает возможных проявлений семантики (и лексико-семантических отношений), структуры (и эволюции словообразовательных моделей), синтаксической роли (и дискурсивной значимости) предлогов в языке вообее. Представленная ниже типология предлогов строится по принципу открытой классификации [16; 17], имеющей вакантные позиции, то есть имеет также и проспективный характер. При создании данной типологии за основу принята иерархическая модель системы языка.

Для достижения поставленной цели решаются следующие конкретные исследовательские задачи:

1) выявить своеобразие типологии предлогов в русском, английском и немецком языках в следующих аспектах:

- эволюционном;

- фонетико-фонологическом;

- семантическом;

- структурном;

- морфологическом;

- синтаксическом;

- стилистическом;

- дискурсивном.

Построить собственную (авторскую) типологию предлогов, объединяющую в своей многоуровневой систематизации все особенности выявленных семантических и функциональных свойств предлогов в анализируемых языках;

2) сопоставить пространственные и временные предлоги русского, английского и немецкого языков с использованием одноязычных и двуязычных словарей. Определить возможные причины нарушения употребления данных предлогов в исследуемых языках.

Решение поставленных задач осуществляется с помощью комплекса научно-исследовательских методов, частнонаучных (лингвистических) и общенаучных. Среди лингвистических методов использованы дескриптивный, сопоставительный методы, семантический и компонентный анализ художественных текстов на английском, немецком и русском языках, метод словарных дефиниций. Среди общенаучных методов активное применение нашли гипотетико-дедуктивный метод, моделирование, типологизация, количественный анализ и графическая интерпретация полученных данных.

Теоретической базой настоящего исследования послужили фундаментальные работы в области семантики и когнитивной лингвистики, представленные трудами отечественных и зарубежных ученых по следующим направлениям:

- семантика и прагматика: Ю. Д. Апресян, Т. И. Арбекова, И. В. Арнольд, А. С. Ларионова, Ч. Филлмор, Ж. Хабермас и др.;

- морфология и словообразование: А. В. Бондарко, Т. В. Булыгина, В. В. Виноградов, Г. О. Винокур, Б. А. Ильиш, Н. А. Кобрина, Е. С. Кубрякова, А. И. Смирницкий, В. Н. Ярцева и др.;

- синтаксис и теория дискурса: Ш. Балли, М. М. Бахтин, И. Беллерт, В. Г. Борботько, С. Ф. Брюно, Л. С. Выготский, В. Г. Гак, С. И. Гиндин, В. А. Кох, Е. Курилович, Ж. Марузо, Э. Сепир, А. Сешеэ, Б. Уорф, А. Фрей и др.;

- функциональная стилистика: Ф. И. Буслаев, В. В. Виноградов, Г. О. Винокур, М. Н. Кожина, М. В. Ломоносов, Е. Д. Поливанов, Д. Э. Розенталь и др.;

- лингвистическая типология: В. А. Виноградов, Дж. Гринберг, М. А. Журинская, Г. А. Климов, В. А. Плунгян и др.;

- лексикография: И. К. Аделунг, И. Г. Вальтер, В. И. Даль, Ш. Дюканж, С. И. Ожегов, В. Н. Ярцева и др.;

- сопоставительное языкознание: В. А. Богородицкий, И. А. Бодуэн де Куртенэ, Р. Ладо, Е. Д. Поливанов, А.А. Потебня, Л. В. Щерба и др.;

- перевод и межкультурная коммуникация: И. Г. Жирова, Л. Л. Нелюбин, И. Н. Филиппова и др.;

- лингводидактика: М. Берлиц, Г. Блумфилд, Ф. Гуэн, О. Есперсен, Г. Суит, Х. Палмер, Л. В. Щерба и др.

Практическая значимость данной работы заключается в том, что полученные результаты могут быть использованы в ходе подготовки филологов на занятиях по общему, частному и сопоставительному языкознанию, в курсах теории и практики английского и немецкого языков, практике перевода, межкультурной коммуникации. Обнаруженные в ходе исследования особенности межъязыковой корреспонденции предлогов могут послужить основой адаптации учебных пособий по теоретической грамматике, лексикологии и стилистике русского, английского и немецкого языков и способствовать оптимизации лингводидактики в исследуемой области.

Фактический материал изучения составили тексты различной жанрово-стилистической принадлежности на русском, английском и немецком языках и данные лексикографических источников. 


\section{Типология предлогов}

На сегодняшний день в лингвистике не существует законченной классификации предлогов, в опыте построения представляемой ниже типологии используются не взаимоисключающие основания, что позволяет создать совокупную перекрестную схему на интегративном подходе и детально разграничить свойства предлогов. Представляемая схема позволяет дифференцировать предлоги по значимым основаниям, обнаруживая 9 групп и 42 подгруппы.

\section{1. Типология предлогов в эволюционном аспекте}

В эволюционном аспекте предлоги делятся на первообразные и производные. Первообразные предлоги представляют собой небольшую и не пополняющуюся группу простейших многозначных слов, у которых есть возможность соединения с двумя и более падежными формами имени: без, в, для, до, зa, uz; in, on, at, to, under; auf, in, vor, an и др. Производные предлоги являются результатом лексико-синтаксического способа словообразования, то есть обособления словоформы лексемы: в течение, в продолжение, вокруг; alongside, outside, within, wherewith; angesichts, anhand, anlässlich, entsprechend, innerhalb и др.

\section{2. Типология предлогов на фонетико-фонологическом уровне}

На фонетико-фонологическом уровне можно выделить постоянно безударные предлоги, не имеющие самостоятельного ударения и как проклитики образующие с существительным единое фонетическое слово: на доро́ze, on the weekend (на выходных) (здесь и далее перевод выполнен автором статьи. - E. 3.), at five o'clóck (в пять часов), inmitten eines Prozésses (в середине процесса), auf dem Téppich (на ковре). Конвенционально ударными мы называем предлоги, принимающие ударение в рамках единого фонетического слова с единицей самостоятельной части речи в роли энклитика. Данная модель достаточно распространена в русском языке, в отличие от английского и немецкого, и используется в определенных стилистических целях: на́ ночь, по́д руки, бе́з году и др. Несинтагменно ударные предлоги имеют самостоятельное ударение, но не могут составить акцентный центр синтагмы: в тече́ние ме́сяца, по проше́ствии полугóda, in his 'flat (в его квартире), im Láufe der Zéit (со временем), infólge der fréundlichen Zústimmung (в результате дружеского одобрения). На главноударных предлогах локализуется фразовый акцент - для реализации особой коммуникативной задачи: ищи на́ столе, а не под столом [12], She finished `writing and went ’out. / Она закончила писать и ушла.

\section{3. Типология предлогов по качественным показателям семантики}

По качественным показателям семантики были выделены только локальные: om, y, pядом, через; through, along, out of, from; über, unter, neben, zwischen, - и темпоральные: через, до, с, после, перед; at, in, on, since, for; während, bis, bei. Пространственные и временные предлоги в русском, английском и немецком языках носят системно-структурный семантический характер, другие семантические подгруппы предлогов выходят за рамки настоящего исследования, поэтому не детализируются далее, оставляя значительный простор для расширения представляемой типологии. С точки зрения количественных показателей семантики предлогов выделяются моносемные и полисемные предлоги. Предлоги, сочетающие временное значение с пространственным, на работе / на столе, im Himmel / in der Konferenz отличаются от синкретичных, имеющих в своей семантике пространственное или временное значение с прочими компонентами под деревом / под парусом / под суд, auf dem Berliner Messegelände (в берлинском выставочном центре), auf Platz zwei (на втором месте), auf Fremde offen zugehen (быть omкрытым для незнакомцев) / auf die Frage antworten (отвечать на вопросы), auf den Beinen sein (стоять на ногах).

\section{4. Типология предлогов в структурном аспекте}

В структурном аспекте предлоги можно классифицировать в количественном плане, выделяя ординарные и составные предлоги. Простые предлоги русскоязычные под, над, c, om, до, после, ввиду, вследствие, вместо, путем, английские at, after, under, before, on, in, немецкие ab, vor, nach, in, seit, anstatt, zurzeit «состоят из одного слова» [2, с. 517]. К составным предлогам относятся непервообразные, состоящие из двух или трех слов: «...формы имени, деепричастия или наречия в сочетании с одним или двумя первообразными предлогами» [Там же, с. 519]. При детальном анализе качественного аспекта предлогов были отмечены конверсионные предлоги (образованные в результате конверсии - перехода в предлоги из другой части речи при соположении компонентов): в соответствии с, несмотря на, вплоть до, в силу, при помощи, в связи с, an Stelle $\rightarrow$ anstelle, an Hand $\rightarrow$ anhand, auf Grund $\rightarrow$ aufgrund, in front of, in spite of. Деривативные предлоги демонстрируют использование определенных моделей словопроизводства. Наибольшей частотностью в пределах фактического материала исследования обладает аффиксация: меж - между - промеж - промежду, среди - посреди; in der Mitte $\rightarrow$ inmitten, zur Folge $\rightarrow$ zufolge, im Hinsicht auf $\rightarrow$ hinsichtlich, zum Anlass von $\rightarrow$ anlässlich, Wille $\rightarrow($ um) ...willen, zu j-des Liebe $\rightarrow$ zulieb. Далее, по типу семантико-синтаксической связи, лежащей в основе создания производного предлога, можно дифференцировать коппулативные единицы, объединяющие в комплекс два равноценных предлога с новым семантическим наполнением из-за, по-над, из-под, уникальные на материале русского языка, которые есть основания считать эндоморфными (пока не обнаружены тождественные образования на материале других языков, не вошедших в эмпирическую базу настоящего исследования). Комплементарными предлагаем называть предлоги, которые при соположении (чаще дистантном) сохраняют 
свое первоначальное значение, при этом у новой единицы детализируется семантика (пространственная или временная), такие языковые факты отмечены только в немецком языке: auf Mitternacht zu (ближе к полуночи), aus den Augenwinkeln heraus (краем глаза), von sich aus (сам по себе), nach der anderen Seite zu (на другую сторону), gegen die Straße zu (против дороги), von klein auf (с раннего возраста).

\section{5. Типология предлогов в морфологическом аспекте}

Осмысление морфологической природы предлога (как в широком, так и в узком смысле) позволяет выделить моновариантные и поливариантные предлоги. Моновариантные предлоги не обладают ни стилистическими (просторечными, диалектными, ограниченными сферой функционирования), ни диахроническими (архаичными) вариантами. Поливариантными считаем предлоги, имеющие хотя бы один вариант или несколько разных: работать близко к дому - близко от дома - близко с домом (вариантными являются предлоги в семантически стабильных словосочетаниях). Поливариантность объемлет семантически тождественные единицы: перед nред(о), над - по-над, wegen - von wegen, nach - nach ... zu, von - von ... auf, on the weekend - at the weekend.

\section{6. Типология предлогов в синтаксическом аспекте}

В синтаксическом аспекте выделены следующие группы предлогов: строго препозиционные, интерпозиционные, вариантно постпозиционные, постпозиционные, дистантные и редуплицируемые. Строго препозиционных предлогов во всех исследуемых языках абсолютное большинство, прочие группы количественно менее репрезентативны. В русском языке эндоморфные интерпозиционные предлоги обнаруживаются в употреблении с двучастными местоимениями: друг для друга, ни о чем, кое с кем, друг за другом. Вариантно постпозиционные предлоги могут быть использованы и в пре-, и в постпозиции: сердиу вопреки - вопреки воле отца, судьбе навстречу - навстречу счастью, nach seinem Rat - теiner Meinung nach (следуя его совету - на мой взгляд), entgegen seinen Erwartungen - seiner Wille entgegen (против его ожиданий - против его воли). Постпозиционные (или склонные к постпозиционной локализации) предлоги достаточно редки в исследуемых языках: dem Bericht zufolge (согласно отчету), dem Freitag zum Anlass (по случаю пятницы). Дистантное расположение предлогов представляет рамочную конструкцию, обрамляющую определяемый компонент словосочетания: von diesem Standpunkt aus (с этой точки зрения), von klein auf (с раннего возраста), von Kindheit an (с детства), am Meer entlang (вдоль моря), von der Wiege an (с пеленок). Особенно активна рамочная локализация предлога в немецком языке - один предлог способен сочетаться с несколькими разными единицами: von Amts wegen, von Berufs wegen, von Rechts wegen, von Staats wegen, представляя факты эндоморфизма. В английском языке дистантное расположение возможно только в специальном вопросе, где предлог занимает финальную позицию, в соответствии с синтаксической конструкцией «замыкания» [9, с. 47-49] и составляя рамку с вопросительным словом: Who are you going to cooperate with? / С кем ты собираешься сотрудничать?; What are you talking about? / О чем ты говоришь?; What is he looking at? / На что он смотрит? Редуплицируемые предлоги составляют тенденцию, закреплены нормой языка и представлены в русском и немецком языках: подбросить под потолок, снять с полки, добраться до дома, внедриться в подполье, зайти за предел, Mitleid mit jemandem haben (жалеть кого-то), an etwas herantreten (приблизиться к чему-то), nach еinem Wort im Lexikon nachschlagen (искать слово в словаре). Дублируемые предлоги не составляют современную норму литературного языка, используются кратно в составе одного словосочетания - при определении и определяемом существительном, частотны в русском языке, особенно в народно-поэтической речи и в песенном дискурсе: ...выходила на берег Катюша, на высокий, берег на крутой [10].

\section{7. Типология предлогов в стилистическом аспекте}

Употребляясь в текстах разных стилей, предлоги могут быть нейтральными, составляющими основу фонда этого класса единиц и количественно преобладающими во всех исследуемых языках, и стилистически окрашенными, способными внести вклад в стилистический уровень организации высказывания, повышая выразительность, контрастность, экспрессию повтора и т.п. Подобные предлоги можно дополнительно классифицировать на подгруппы в соответствии со сферой их употребления. Профессионально маркированные предлоги представлены в немецком языке: die Ware ist per ersten Mai lieferbar (товар должен быть доставлен 1 мая), реr sofort (немедленно). Архаичные предлоги обусловлены вытеснением части единиц в пассивный слой лексики, опознаются носителями языка как устаревшие и вышедшие из активного употребления и - как правило - сопровождаются соответствующими словарными пометами в лексикографических источниках: меж (вытесненный между), о (в темпоральном значении вытесненный на): о масленице блины пекли, окрест (вытесненный вокруг): И все пустынно стало окрест меня и предо мной [5]... Диалектные округ и обапол (вместо вокруг), по-под, по-за, по-на, по-перед: по-под горою тракторы пашут; по-за кожу заноза вошла, просторечные посередь, промеж; про в значении для: это не про тебя, с в значении из: приехали с Москвы; пришел со школы; Мы в концерт идем [12]. К национально маркированным предлогам можно отнести: за (еврейское: я вам не скажу за всю Одессу, я за него ничего не знаю), per, pro (в немецком языке), contra, pro, exclusive, inklusive, minus, plus, via. Народнопоэтическая речь в русском языке сохранила диалектные формы, которые со временем приобрели новый стилистический оттенок: по-над водой, по-над лесом, по-за рекой, по-над берегом, по-над [3]. Как он тянется, // Так останется, // По-над по́лем, по-над лесом // Перевесом, // Любо мне, // Любо, любо, любо [14]. 


\section{8. Типология предлогов в дискурсивном аспекте}

В дискурсивном пространстве на функционирование предлогов оказывают серьезное влияние многочисленные внешние языковые и экстралингвистические языковые факторы. Дискурсивно незначимыми являются большинство предлогов в неинституциональных типах дискурса. Высокой коммуникативной значимостью обладают предлоги в соответствии с прагматикой дискурса: научного вследствие, в сопоставлении, на основании, по завершении, mittels, zwecks, anlässlich, mangels, mithilfe, according to, despite the fact that, taking into account или юридического в силу, в случае, по мере, в соответствии с, в интересах, im Hinsicht auf, von ...wegen, im Bezug auf, über ... hinweg. Дискурсивно маркированные предлоги обусловлены прагматической задачей автора в поэтических и прозаических произведениях, обладающих яркой идиостилистикой и раскрывающих индивидуальную концептуальную картину мира (подробнее см. [6]).

\section{Сопоставление предлогов}

Сопоставление пространственных и временных предлогов русского, английского и немецкого языков с использованием одноязычных и двуязычных словарей $[4 ; 8 ; 11 ; 13]$ показало, что корреспонденция предлогов сопряжена с известными трудностями, так как семантические объемы совпадают не полностью. Прогностически исключать возможность полно коррелирующих предлогов не стоит, но в анализируемом материале абсолютной эквивалентности не обнаружено. В межъязыковом (переводческом) аспекте предлоги следует разделить на частично коррелирующие (совпадающие лишь в одном или нескольких семантических компонентах в разных языках), лакунарные (не имеющие эквивалентов), интерферирующие положительно (демонстрирующие тенденцию к межъязыковой симметрии [15]) и интерферирующие отрицательно (обнаруживающие тенденцию к расхождению в языковых парах) (подробнее см. [7]).

\section{Заключение}

Подводя итоги представленной типологии предлогов в соответствии с небинарной оппозицией по таксономическому принципу, можно сделать следующие выводы.

1. Выявленное своеобразие типологии предлогов в русском, английском и немецком языках в различных аспектах позволяет разработать универсальную, апплицируемую к любым языкам типологию, которая в структурном отношении открыта и имеет потенциальную возможность к расширению для вмещения новых языковых фактов (Таблица 1).

В данной типологии для классификации предлогов используются не взаимоисключающие основания, что позволяет создать перекрестную схему и детально разграничить свойства предлогов.

Представленная типология позволила систематизировать знания о предлогах в русле универсализации, а также ввести в терминооборот новые научные понятия, характеризующие предлоги.

Таблица 1. Собственная (авторская) типология предлогов

\begin{tabular}{|c|c|c|c|}
\hline \multirow[t]{2}{*}{ 1. в аспекте эволюции } & \multicolumn{3}{|l|}{ 1.1. первообразные } \\
\hline & \multicolumn{3}{|l|}{ 1.2. производные } \\
\hline \multirow[t]{4}{*}{ 2. в аспекте фонологии } & \multicolumn{3}{|l|}{ 2.1. проклитики } \\
\hline & \multicolumn{3}{|c|}{ 2.2. конвенционально ударные } \\
\hline & \multicolumn{3}{|c|}{ 2.3. несинтагменно ударные } \\
\hline & \multicolumn{3}{|l|}{ 2.4. главноударные } \\
\hline \multirow[t]{5}{*}{ 3. в аспекте семантики } & \multirow[t]{2}{*}{ 3.1. качественно } & \multicolumn{2}{|c|}{ 3.1.1. пространственные } \\
\hline & & \multicolumn{2}{|l|}{ 3.1.2. временные } \\
\hline & \multirow[t]{3}{*}{ 3.2. количественно } & 3.2.1. моносемные & \\
\hline & & \multirow[t]{2}{*}{ 3.2.2. полисемные } & $\begin{array}{l}\text { 3.2.2.1. только } \\
\text { в пространственном значении }\end{array}$ \\
\hline & & & $\begin{array}{l}\text { 3.2.2.2. только } \\
\text { в темпоральном значении }\end{array}$ \\
\hline \multirow[t]{7}{*}{ 4. в аспекте структуры } & \multirow[t]{3}{*}{ 4.1. по количеству } & \multicolumn{2}{|l|}{ 4.1.1. простые } \\
\hline & & \multirow[t]{2}{*}{ 4.1.2. составные } & 4.1.2.1. двучастные \\
\hline & & & 4.1.2.2. трехчастные \\
\hline & \multirow[t]{4}{*}{ 4.2. по качеству } & \multicolumn{2}{|c|}{ 4.2.1. конверсионные } \\
\hline & & \multicolumn{2}{|l|}{ 4.2.2. деривативные } \\
\hline & & \multicolumn{2}{|l|}{ 4.2.3. коппулативные } \\
\hline & & \multicolumn{2}{|c|}{ 4.2.4. комплементарные } \\
\hline \multirow[t]{2}{*}{ 5. в аспекте морфологии } & \multicolumn{3}{|l|}{ 5.1. моновариантные } \\
\hline & \multicolumn{3}{|l|}{ 5.2. поливариантные } \\
\hline \multirow[t]{3}{*}{ 6. в аспекте синтаксиса } & \multicolumn{3}{|c|}{ 6.1. строго препозиционные } \\
\hline & \multicolumn{3}{|c|}{ 6.2. интерпозиционные } \\
\hline & \multicolumn{3}{|c|}{ 6.3. вариантно постпозиционные } \\
\hline
\end{tabular}




\begin{tabular}{|c|c|c|}
\hline & \multicolumn{2}{|l|}{ 6.4. строго постпозиционные } \\
\hline & \multicolumn{2}{|l|}{ 6.5. д дистантные (рамочные) } \\
\hline & \multicolumn{2}{|l|}{ 6.6. редуплицируемые } \\
\hline & \multicolumn{2}{|l|}{ 6.7. дублируемые } \\
\hline \multirow[t]{7}{*}{ 7. в аспекте стилистики } & \multicolumn{2}{|l|}{ 7.1. общеупотребительные } \\
\hline & \multirow[t]{6}{*}{ 7.2. м маркированные } & 7.2.1. профессиональные \\
\hline & & 7.2.2. архаичные \\
\hline & & 7.2.3. диалектные \\
\hline & & 7.2.4. просторечные \\
\hline & & 7.2.5. национальные \\
\hline & & 7.2.6. народно-поэтические \\
\hline \multirow[t]{3}{*}{ 8. в аспекте дискурса } & \multicolumn{2}{|l|}{ 8.1. незначимые дискурсивно } \\
\hline & \multirow[t]{2}{*}{ 8.2. дискурсивно значимые } & 8.2.1. по прагматике дискурса \\
\hline & & 8.2.2. по прагматике автора \\
\hline \multirow{4}{*}{$\begin{array}{l}\text { 9. в межъязыковом } \\
\text { аспекте }\end{array}$} & \multicolumn{2}{|l|}{ 9.1. полно коррелирующие } \\
\hline & \multicolumn{2}{|l|}{ 9.2. частично коррелирующие } \\
\hline & \multicolumn{2}{|c|}{ 9.3. интерферирующие положительно } \\
\hline & \multicolumn{2}{|c|}{ 9.4. интерферирующие отрицательно } \\
\hline
\end{tabular}

2. Сопоставление пространственных и временных предлогов русского, английского и немецкого языков с использованием одноязычных и двуязычных словарей позволило выявить: различия в концептуализации пространства и времени в ИЯ (русском) и ПЯ (английском и немецком); недостаточность языковой компетенции в области ПЯ, особенно второго иностранного языка (в нашем случае - английского и немецкого); а также заключить, что большинство ошибок в употреблении предлогов данной категории связано с расхождением языковой картины мира в ИЯ и ПЯ.

Представления пространства и времени в русской, британской и немецкой лингвокультурах различны и предопределяют многочисленные затруднения в межъязыковой коммуникации, требуя развитых навыков перевода и готовности видеть мир глазами другой нации.

В завершение отметим, что объективные расхождения норм, узусов, языковых картин мира в ИЯ и ПЯ не могут служить оправданием низкого качества перевода, а служат факторами мобилизации и самокритичности для эффективного повышения языковой и переводческой компетенции, которые позволяют преодолеть интерферирующее влияние родного языка на способ выражения ИТ средствами ПЯ и активизировать иное межъязыковое и широкое коммуникативное видение переводчика.

Дальнейшая перспектива исследования видится в расширении эмпирической базы и выявлении новых подтипов предлогов на материале иных национальных языков и временных пластов, в пополнении системы знаний о семантических группах предлогов, оставшихся за рамками настоящей работы (причинные, целевые, объектные и пр.).

\section{Источники | References}

1. Бондаренко В. С. Предлоги в современном русском языке. М.: Учпедгиз, 1961. 74 с.

2. Виноградов В. В. Русский язык. Грамматическое учение о слове. Изд-е 3-е. М.: Рус. яз., 1986. 601 с.

3. Высоцкий В. С. Кони привередливые [Электронный ресурс]. URL: https://www.culture.ru/poems/19303/konipriveredlivye (дата обращения: 23.09.2020).

4. Даль В. И. Толковый словарь живого великорусского языка [Электронный ресурс]. URL: https://gufo.me/ $\mathrm{dict} / \mathrm{dal}$ (дата обращения: 26.01.2021).

5. Жуковский В. А. Мечты [Электронный ресурс]. URL: http://www.world-art.ru/lyric/lyric.php?id=13124 (дата обращения: 23.09.2020).

6. Зайцева Е. М. Дискурсивная значимость предлогов (на материале русского и английского языков) // Теория языка и межкультурная коммуникация. 2021. № 1 (40). С. 83-94.

7. Зайцева Е. М. Оптимизация переводческих навыков студентов (в рамках межъязыковой корреспонденции предлогов) // Междисциплинарный подход к подготовке современного педагога: науч.-метод. конф. М.: МГОУ, 2020. С. 29-42.

8. Иванова О. Е., Лопатин В. В., Нечаева И. В., Чельцова Л. К. Русский орфографический словарь. М.: Ин-т рус. яз. им. В. В. Виноградова, 2016. 882 с.

9. Ильиш Б. А. Современный английский язык. М.: Изд-во лит. на иностр. яз., 1948. 348 с.

10. Исаковский М. Катюша [Электронный ресурс]. URL: https://www.culture.ru/poems/36467/katyusha (дата обращения: 23.09.2020).

11. Лингвистический энциклопедический словарь. Предлог [Электронный pecypc]. URL: http://tapemark. narod.ru/les/394a.html (дата обращения: 23.09.2020).

12. Меньшов В. В. Москва слезам не верит [Электронный ресурс]. URL: https://www.ivi.ru/watch/moskva_ slezam_ne_verit/season1 (дата обращения: 23.09.2020).

13. Нелюбин Л. Л. Толковый переводоведческий словарь. Изд-е 3-е, перераб. М.: Флинта; Наука, 2003.320 с. 
14. Островский А. Н. Снегурочка [Электронный ресурс]. URL: https://ilibrary.ru/text/1200/p.1/index.html (дата обращения: 23.09.2020).

15. Филиппова И. Н. Вербальная недостаточность и переводческая компетенция // Научное мнение. 2012. № 4. С. 17-22.

16. Филиппова И. Н. Классификация вербальной избыточности // Вестник Московского государственного областного университета. Серия «Лингвистика». 2011. № 1. С. 150-155.

17. Филиппова И. Н. Классификация вербальной недостаточности // Вестник Челябинского государственного университета. 2013. № 35 (326). С. 130-134.

18. Щерба Л. В. О частях речи. Избранные работы по русскому языку: науч. изд-е. М.: Учпедгиз, 1957. 188 с.

\section{Информация об авторах | Author information}

RU Салеева (Зайцева) Екатерина Михайловна ${ }^{1}$

${ }^{1}$ Московский государственный областной университет

EN Saleeva (Zaytseva) Ekaterina Mikhailovna ${ }^{1}$

${ }^{1}$ Moscow Regional State University

${ }^{1}$ katrin95.95@mail.ru

Информация о статье | About this article

Дата поступления рукописи (received): 16.07.2021; опубликовано (published): 15.09.2021.

Ключевые слова (keywords): предлоги; универсальная классификация; изоморфизм; алломорфизм; эндоморфизм; prepositions; universal classification; isomorphism; allomorphism; endomorphism. 